\title{
Editorial: REE Marine Geochemistry in the 21st Century: A Tribute to the Pioneering Research of Henry Elderfield (1943-2016)
}

\author{
Johan Schijf ${ }^{1 *}$, Catherine Jeandel ${ }^{2}$, Karen H. Johannesson ${ }^{3}$ and Anne H. Osborne ${ }^{4}$ \\ ${ }^{1}$ Chesapeake Biological Laboratory, University of Maryland Center for Environmental Science, Solomons, MD, United States, \\ ${ }^{2}$ LEGOS, Université Toulouse III-Paul Sabatier (CNRS, UPS, IRD, CNES), Toulouse, France, ${ }^{3}$ School for the Environment, \\ University of Massachusetts Boston, Boston, MA, United States, ${ }^{4}$ GEOMAR, Helmholtz Centre for Ocean Research, Kiel, \\ Germany
}

Keywords: Henry Elderfield, rare earth elements (REE), Nd isotopes, seawater, mass balance, trace metal cycling, scavenging, boundary exchange

\section{Editorial on the Research Topic}

REE Marine Geochemistry in the 21st Century: A Tribute to the Pioneering Research of Henry Elderfield (1943-2016)

This Research Topic (RT), inspired by an identically titled special session at the 2017 ASLO Aquatic Sciences Meeting in Honolulu, was established in honor and recognition of the pioneering research of Henry (Harry) Elderfield, who passed away in April 2016 after a long career in marine geochemistry. Although Harry's scientific interests and impacts were manifold, he will probably be

\section{OPEN ACCESS}

Edited and reviewed by: Sunil Kumar Singh,

Physical Research Laboratory, India

*Correspondence: Johan Schijf schij@umces.edu

Specialty section: This article was submitted to Marine Biogeochemistry, a section of the journal Frontiers in Marine Science

Received: 19 December 2019 Accepted: 12 February 2020

Published: 04 March 2020

Citation: Schijf J, Jeandel C, Johannesson KH and Osborne AH (2020) Editorial: REE

Marine Geochemistry in the 21st Century: A Tribute to the Pioneering Research of Henry Elderfield

(1943-2016). Front. Mar. Sci. 7:114. doi: 10.3389/fmars.2020.00114 most remembered for his seminal work on the chemical analysis and interpretation of rare earth element (REE) distributions in the ocean. In his early landmark monograph (Elderfield, 1988), which was based on very limited data yet, as several of our authors note, remains relevant to this day, Harry keenly recognized the main REE sources in seawater: rivers, aerosols, hydrothermal vents, and marine sediments. Their relative importance is a major focus of this RT.

Adebayo et al. analyzed water and suspended particles from the Mississippi River estuary, one of the largest in the world. They show HREE-enriched dissolved patterns and a degree of REE removal well below the global average, attributing this to the elevated $\mathrm{pH}$ and extensive complexation with organic ligands. Labile fractions of particles and sediments were found to have more radiogenic $\varepsilon_{\mathrm{Nd}}$ values than the river water. These observations illustrate that the scavenging processes that curtail the riverine REE flux are still not fully understood. Hathorne et al. investigated the temporal and spatial dynamics of REE patterns and $\varepsilon_{\mathrm{Nd}}$ in a 3-year time series of surface water samples from the Bay of Bengal and Andaman Sea. They discuss putative signals of seasonal discharge from major rivers to the north (including the Ganges and Irrawaddy) within the context of regional geology and the influence of the Andaman Islands, aerosols, and exchange between colloidal and particulate REE pools. Their ultimate goal is to examine whether such signals, potentially recorded in coral skeletons, might be used as a geochemical tracer of the Asian summer monsoon. Schijf and Christy measured the stability of the MRI contrast agent Gd-DTPA in the presence of $\mathrm{Mg}$ and $\mathrm{Ca}$ at seawater ionic strength. While this organic complex appears impervious to estuarine scavenging and its global release since the late 1980s has caused Gd anomalies in rivers and coastal seawater to increase by orders of magnitude, their results suggest that competition from $\mathrm{Mg}$ and $\mathrm{Ca}$ may release up to $15 \%$ of the bound Gd. This would have significant implications for the bioavailability of this toxic element in sensitive nearshore ecosystems. Stichel et al. demonstrate substantial Nd 
depletion within the Trans-Atlantic Geotraverse (TAG) hydrothermal plume, accompanied by a shift to more radiogenic $\varepsilon_{\mathrm{Nd}}$ values. Extrapolation to a global estimate, using on-axis heat fluxes, an empirical correlation with excess ${ }^{3} \mathrm{He}$, and comparison with vertical profiles at the nearby unaffected Bermuda Atlantic Time-Series (BATS) station, yields a Nd sink equal to about $70 \%$ of the combined river and dust inputs $(6-8 \%$ of the global REE flux). The $\varepsilon_{\mathrm{Nd}}$ shift confirms that REE scavenging within hydrothermal plumes involves a process similar to marine boundary exchange, but at only $0.1 \%$ of the scale.

Although Harry was already aware of the importance of sediments and porewaters as an oceanic REE source (Elderfield, 1988), he may not then have realized the extent to which this flux was underestimated and likely accounts for the puzzling " $\mathrm{Nd}$ paradox". Using a review of existing data, Haley et al. argue that the Nd paradox is more likely to be reconciled by a "bottom-up" model based on predominantly benthic inputs than by current "top-down" models that emphasize surface inputs and reversible scavenging. They discuss the ramifications of such a model for the interpretation of modern and paleoceanic Nd distributions. Abbott et al. aim to formalize this idea by presenting microspectroscopic analyses of various sediments and pore waters from the Pacific Ocean that promote authigenic clays as the mineral phase primarily responsible for the benthic REE inputs. They propose that REE-Fe correlations, generally interpreted in terms of REE sorption by ferromanganese oxides, may actually be due to control by Fe-rich clay minerals like glauconite.

Two papers study boundary exchange in more detail, but in very different settings. Morton et al. show that the northwest Pacific shelf is the source of an extensive dissolved Mn plume that is oxidized to particulate Mn, possibly by biological activity, and rapidly transported offshore by the Kuroshio Current, while scavenging other redox-sensitive elements like Ce and Co. However, whereas $\mathrm{Mn}$ and $\mathrm{Ce}$ are removed by settling within the coastal zone, the Co signal endures (probably by organic complexation of the higher oxidation state) and can be tracked across most of the Pacific basin. Molina-Kescher et al. measured $\mathrm{REE}$ concentrations and $\varepsilon_{\mathrm{Nd}}$ in coastal, river, and sub-marine

\section{REFERENCES}

Elderfield, H. (1988). The oceanic chemistry of the rare-earth elements. Phil. Trans. Royal Soc. London A 325, 105-126.

Conflict of Interest: The authors declare that the research was conducted in the absence of any commercial or financial relationships that could be construed as a potential conflict of interest. groundwater discharge (SGD) samples throughout Tahiti and in seawater within the predominant circulation downstream of the islands. They find that all terrestrial and coastal seawater samples have a clear signature of the local basaltic rock with elevated MREE concentrations and Eu anomalies and radiogenic $\varepsilon_{\mathrm{Nd}}$ values. The REE pattern characteristics are lost in mid-depth AAIW as it mixes with other water masses, but the isotopic signal persists, indicating that basaltic islands may have a significant capacity for influencing $\varepsilon_{\mathrm{Nd}}$ on basin-wide scales.

The last two papers view oceanic REE cycling from a broader perspective, including benthic and advective processes in the deep ocean, as well as authigenic and/or biologically driven reversible scavenging near the surface. Crocket et al. highlight the role of complex hydrography across the major channels between Iceland and Scotland. Grenier et al. highlight terrestrial inputs across the Kerguelen Plateau in the Indian sector of the Southern Ocean. Both studies were conducted against the backdrop of an incipient spring plankton bloom, conveying clear REE fractionation signals in the upper water column.

If all these excellent papers are any indication, the next decades of REE marine geochemistry promise to be equally exciting. We hope they will be enjoyed by many readers of Frontiers.

\section{AUTHOR CONTRIBUTIONS}

JS wrote the editorial with contributions and final approval from the other three authors, who are listed in alphabetical order. All editors were equal participants in this Research Topic.

\section{ACKNOWLEDGMENTS}

We all owe a debt of gratitude to Harry Elderfield, to whom this RT is dedicated, either for his professional guidance and personal kindness, or as one of the founding fathers of our common research field. We thank all authors of this RT for their contributions and their patience, as well as the reviewers for their time and dedication. This is UMCES contribution \#5754.
Copyright (C) 2020 Schijf, Jeandel, Johannesson and Osborne. This is an open-access article distributed under the terms of the Creative Commons Attribution License (CC $B Y)$. The use, distribution or reproduction in other forums is permitted, provided the original author(s) and the copyright owner(s) are credited and that the original publication in this journal is cited, in accordance with accepted academic practice. No use, distribution or reproduction is permitted which does not comply with these terms. 